\title{
EFEITOS DA MASSAGEM PERINEAL DURANTE O TRABALHO DE PARTO
}

\author{
Mariana Fernandes Lopes \\ Instituto Politécnico de Viseu, Escola Superior de Saúde, Viseu, Portugal \\ essv6098@essv.ipv.pt \\ Emília de Carvalho Coutinho \\ Instituto Politécnico de Viseu, Escola Superior de Saúde, Viseu, Portugal \\ ecoutinhoessv@gmail.com \\ Maria José Santos \\ Universidade de Trás-os-Montes e Alto Douro, Escola Superior de Saúde, Vila Real, Portugal \\ mjsantos@utad.pt \\ Manuela Ferreira \\ Instituto Politécnico de Viseu, Escola Superior de Saúde, Viseu, Portugal \\ mmcferreira@gmail.com \\ Hélia Dias \\ Instituto Politécnico de Santarém, Escola Superior de Saúde, Santarém, Portugal \\ helia.dias@essaude.ipsantarem.pt
}

Recepción Artículo: 23 mayo 2021 Admisión Evaluación: 23 mayo 2021 Informe Evaluador 1: 27 mayo 2021

Informe Evaluador 2: 30 mayo 2021

Aprobación Publicación: 01 junio 2021

\section{RESUMO}

Durante 0 trabalho de parto o traumatismo do períneo é frequente. A massagem perineal é considerada uma técnica que promove a integridade do períneo. Como objetivo pretende-se identificar os efeitos da massagem perineal durante 0 trabalho de parto. Foi realizada uma revisão integrativa da literatura, com pesquisa a 18 de janeiro de 2021. Foram considerados artigos de estudos primários e revisões sistemáticas da literatura, publicados em Português, Inglês e Espanhol, disponíveis nas bases B-ON, PubMed e CINAHL, em texto integral e de livre acesso, no ano de 2016 a 2020. A questão de pesquisa "Quais os efeitos da massagem perineal durante 0 trabalho de parto?" teve por base o método de PI[C]OD. Aquando a pesquisa nas bases de dados com a expressão - "(injury) AND (massage) AND (perineum) AND (labor) obteve-se 53 artigos na Pubmed; já com a expressão - "( perineal trauma OR perineal injury OR perineal tear OR perineal laceration ) AND massage AND ( labor OR delivery ) obteve-se 278 artigos na B-on e 41 na Cinahl, ficando no total com 372 artigos. Após aplicação dos critérios de inclusão do tempo, língua e livre acesso ficaram 110 artigos. De seguida, considerou-se a repetição dos artigos ficando com 85 artigos. Após leitura do título e resumo foram selecionados 11 artigos. Foram assim encontrados 6 artigos agrupados em função do método de pesquisa. Dos resultados encontrados verificou-se que existem benefícios na utilização da massagem perineal durante 0 trabalho de parto. Conclui-se que a realização de massagem perineal 


\section{EFEITOS DA MASSAGEM PERINEAL DURANTE O TRABALHO DE PARTO}

durante 0 trabalho de parto reduz o número de lacerações no períneo, a necessidade de episiotomia, a duração do trabalho de parto, bem como, a dor após o parto. No entanto, é necessário realizar mais estudos.

Palavras-chave: períneo; traumatismo; massagem; trabalho de parto

\section{ABSTRACT}

Effects of perineal massage during labor. During labor, trauma to the perineum is frequent. Perineal massage is considered a technique that promotes the integrity of the perineum. with the objective to identify the effects of perineal massage during labor. An integrative literature review was carried out, with research on January 18, 2021. Articles from primary studies and systematic literature reviews were published, published in Portuguese, English and Spanish, available in B-ON, PubMed and CINAHL databases, in text full and open access, in the year 2016 to 2020. The research question "What are the effects of perineal massage during labor?" was based on the PI [C] OD method. When searching the databases with the expression - "(injury) AND (massage) AND (perineum) AND (labor), 53 articles from Pubmed; already with the expression - "(perineal trauma OR perineal injury OR perineal tear OR perineal laceration) AND massage AND (labor OR delivery) 278 articles in B-on and 41 in Cinahl, with a total of 372 articles. After application, the criteria for inclusion of time, language and free access, 110 articles remained. Then, the repetition of the articles was considered, leaving 85 articles. After reading the title and summary, 11 articles were selected. Thus, 6 articles were found grouped according to the research method. From the results found there are benefits in using perineal massage during labor. It is concluded that performing a perineal massage during labor reduces the number of lacerations in the perineum, the need for episiotomy, the duration of labor, as well as pain after delivery. However, further studies are needed.

Keywords: perineum; injury; massage; labor

\section{INTRODUÇÃO}

0 parto por via vaginal muitas vezes está associado ao traumatismo do períneo, essencialmente, durante 0 período expulsivo do trabalho de parto. Pelo que 0 cuidado à parturiente durante 0 trabalho de parto tem como um dos enfoques a promoção da integridade do períneo (Zukoff, Pereira, Rafael, \& Penna, 2019).

0 trauma perineal pode, por um lado ocorrer, espontaneamente ou, por outro, estar associado à realização de episiotomia (Botelho, 2017).

A episiotomia é a incisão realizada ao nível do períneo de forma a aumentar o canal vaginal. Nos dias de hoje a episiotomia já começa a ser realizada de forma seletiva. No entanto, ainda não foram definidos os critérios para a execução da mesma, por falta de evidência científica, pelo que o "juízo clínico individual deve prevalecer para guiar a decisão de efetuar este procedimento" (Henriques, 2017, p.580). As episiotomias mais conhecidas são a mediana e a médio-lateral, sendo esta última a mais utilizada na Europa. No entanto, é de considerar que a episiotomia mediana provoca menor hemorragia, é menos dolorosa e é mais fácil de reparar, em contrapartida, tem maior probabilidade de se prolongar até ao esfíncter anal e reto (Henriques, 2017).

Quanto às lacerações, as mesmas são classificadas de primeiro grau quando envolvem apenas a pele do períneo, de segundo grau quando envolvem os músculos do períneo, de terceiro grau aquelas que já se prolongam até ao esfíncter anal, sendo que dentro destas existe uma subdivisão (3a, em que a laceração atinge menos de 50\% do esfíncter anal externo; 3b, em que atinge mais de 50\% do esfíncter anal externo; 3c, todo o esfíncter anal é atingido), por fim, as lacerações de quarto grau que se estendem, para além das estruturas referidas, até à parede anterior do reto. As lacerações de terceiro e quarto grau deixam, muitas vezes cicatrizes na vida da mulher, a longo e curto prazo. A curto prazo considera-se maior perda de sangue durante o parto, a dor no períneo, maior tempo de recuperação no pós-parto e a ligação entre a díade mãe/filho pode ficar comprometida. A longo prazo, a mulher pode ter incontinência urinária e fecal, bem como, dispareunia (Aasheim et al., 2011 cit. por Botelho, 2017; Lowdermilk \& Perry, 2006).

A existência de laceração perineal está, muitas vezes, relacionada com a idade avançada da grávida, a hereditariedade (por exemplo, mulheres ruivas têm a pele mais friável, logo mais suscetíveis a lacerações), ser primí- 
para, o peso do recém-nascido (macrossomia), assim como a realização de indução do trabalho de parto, de episiotomia e ser parto instrumentado (Lowdermilk \& Perry, 2006).

Tendo em vista as complicações que podem advir após a ocorrência de laceração perineal durante o trabalho de parto, é fundamental utilizar estratégias que possam reduzir a probabilidade de as mesmas surgirem. Uma dessas estratégias é a massagem perineal durante o trabalho de parto, que consiste na "aplicação de dois dedos na vagina em direção ao reto, aplicando uma ligeira pressão descendente, movendo os dedos com movimentos constantes" (OMS, 2018, p.139). Esta técnica de baixo custo "pode aumentar a flexibilidade dos músculos perineais, reduzindo assim a resistência muscular, fazendo com que o períneo se distenda durante o trabalho de parto sem rotura e sem necessidade de episiotomia" (Botelho, 2017, p.18).

Assim, tendo em conta que a massagem perineal pode ter um efeito positivo no que toca à integridade perineal durante o trabalho de parto, entre outros, levantou-se como questão de pesquisa para esta revisão integrativa da literatura: "Quais os efeitos da massagem perineal durante o trabalho de parto?".

\section{OBJETIVOS DA INVESTIGAÇÃO}

Determinando como objetivo identificar os efeitos da massagem perineal durante o trabalho de parto.

\section{METODOLOGIA}

Trata-se de uma revisão integrativa de literatura, sendo esta uma abordagem metodológica mais ampla, que permite incluir tanto estudos primários como secundários para que se consiga uma compreensão mais abrangente do tema em análise (Souza, Silva, \& Carvalho, 2010).

A questão de pesquisa teve por base 0 método de PI[C]OD (Participantes, Intervenção, Comparação, Outcomes/resultados, Desenho). Definiu-se assim, como participantes (P) as parturientes; como intervenção (I) a aplicação de massagem perineal; como outcomes/resultado (0) os efeitos da aplicação de massagem perineal; 0 desenho do estudo (D) enquadra-se em estudos primários e revisões sistemáticas da literatura. 0 terceiro ponto do acrómio (C) não foi utilizado. Ficando assim como questão de pesquisa "Quais os efeitos da massagem perineal durante 0 trabalho de parto?".

Elaborada a questão e definido o objetivo, realizou-se a pesquisa a 18 de janeiro de 2021 nas bases de dados B-on, Pubmed e Cinahl. Os descritores DeCS/MeSH utilizados foram Perineum, Injury, Massage, labor, no entanto, para obter o maior número de resultados também foram utilizados os seguintes descritores não controlados perineal trauma, perineal injury, perineal tear e perineal laceration, já os operadores booleanos utilizados para a pesquisa foram o AND e o OR. Como critérios de inclusão considerou-se uma linha temporal de janeiro de 2016 a dezembro de 2020, todos os artigos de língua portuguesa, inglesa e espanhola, de livre acesso, o fenómeno de interesse ser a massagem perineal e o contexto em trabalho de parto. Como critérios de exclusão consideraramse: artigos com ano inferior a 2016, que sejam de língua que não a portuguesa, inglesa e espanhola, que não sejam de livre acesso, o fenómeno de interesse abordar outro método que não a massagem perineal e fora do contexto do trabalho de parto.

Aquando a pesquisa nas bases de dados com a expressão - "(injury) AND (massage) AND (perineum) AND (labor) obteve-se 53 artigos na Pubmed; já com a expressão - "( perineal trauma OR perineal injury OR perineal tear OR perineal laceration ) AND massage AND ( labor OR delivery ) obteve-se 278 artigos na B-on e 41 na Cinahl, ficando no total com 372 artigos. Após aplicação dos critérios de inclusão do tempo, língua e livre acesso ficaram 110 artigos. De seguida, considerou-se a repetição dos artigos ficando com 85 artigos. Após leitura do título e resumo foram selecionados 11 artigos. Após a leitura do texto integral foram excluídos 5 artigos, restando 6 artigos que integraram 0 corpo da pesquisa, conforme figura 1, com 0 PRISMA 2009 adaptado de Joanna Briggs Institute (JBI) (Galvão, Pansani, \& Harrad, 2015). 
Figura 1- Inclusão de artigos pelo Prisma 2009 adaptado de JBI (Galvão et al., 2015)

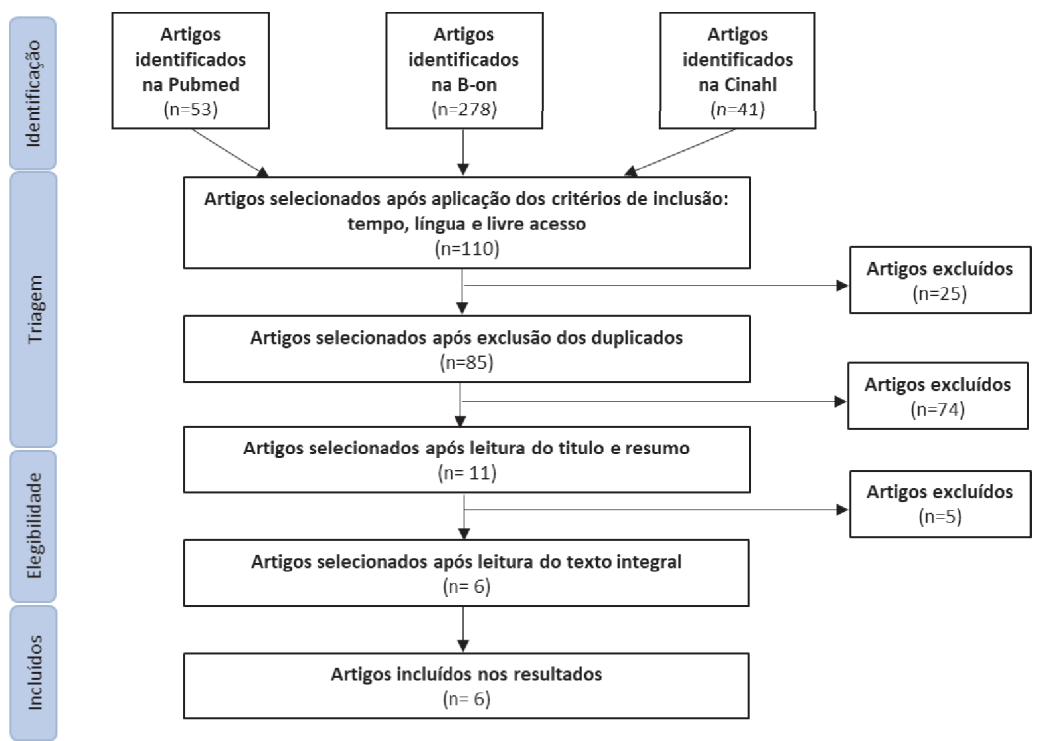

\section{RESULTADOS ALCANÇADOS}

Após a elaboração da pesquisa de artigos nas bases de dados e a sua seleção tendo em conta os critérios de inclusão e de exclusão apresentam-se os mesmos no quadro 1. 
Quadro 1- Quadro com uma breve síntese dos resultados obtidos para a revisão

\begin{tabular}{|c|c|c|c|c|}
\hline Título/Autor/ano & Objetivos & Participantes & Metodologia & $\begin{array}{l}\text { Principais } \\
\text { Resultados }\end{array}$ \\
\hline $\begin{array}{l}\text { 1. The effect of } \\
\text { perineal massage } \\
\text { during the } \\
\text { second stage of } \\
\text { birth on } \\
\text { nulliparous } \\
\text { women perineal: } \\
\text { A } \\
\text { randomization } \\
\text { clinical trial } \\
\text { Shahoei, R., } \\
\text { Zaheri F., Nasab, } \\
\text { L. H., \& Ranaei F. } \\
\text { (2017) }\end{array}$ & $\begin{array}{l}\text { Determinar } \\
\text { o efeito da } \\
\text { massagem } \\
\text { perineal no } \\
\text { segundo } \\
\text { período do } \\
\text { trabalho de } \\
\text { parto nas } \\
\text { lacerações } \\
\text { perineais, } \\
\text { episiotomia } \\
\text { e dor } \\
\text { perineal em } \\
\text { mulheres } \\
\text { primíparas }\end{array}$ & $\begin{array}{l}\text { 195parturientes } \\
\text { (primíparas) } \\
\text { entre as } 38 \text { e } 42 \\
\text { semanas de } \\
\text { gestação, no } \\
\text { Be'sat Hospital } \\
\text { em Sanandaj, } \\
\text { entre o ano de } \\
2013 \text { e } 2014\end{array}$ & 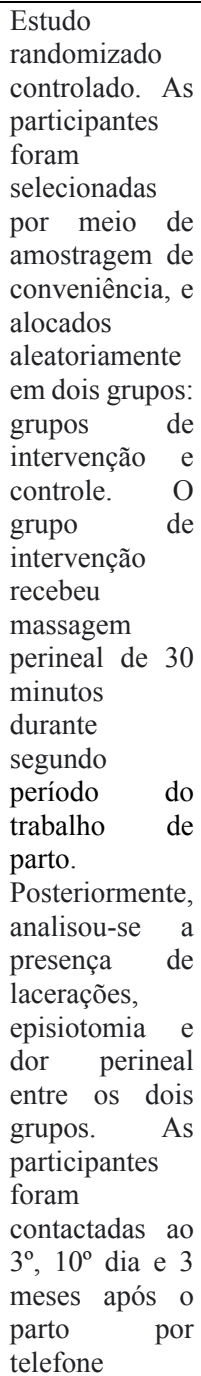 & 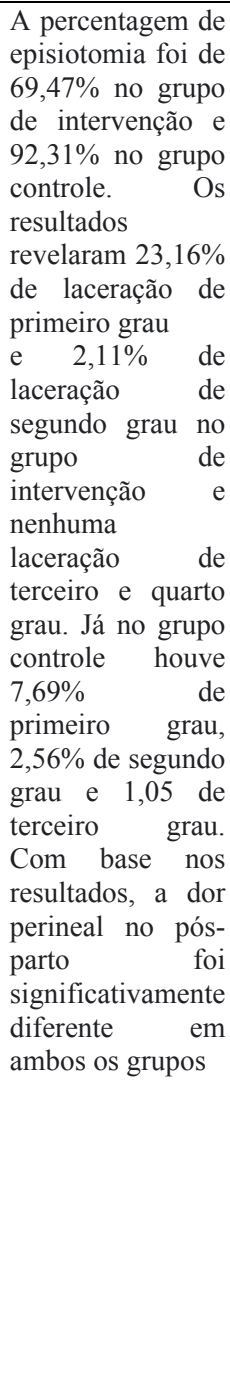 \\
\hline $\begin{array}{l}\text { 2.Effectiveness } \\
\text { of Perineal } \\
\text { Massage in the } \\
\text { Second Stage of } \\
\text { Labor in }\end{array}$ & $\begin{array}{l}\text { Investigar o } \\
\text { efeito da } \\
\text { massagem } \\
\text { perineal no } \\
\text { segundo } \\
\text { período do }\end{array}$ & $\begin{array}{l}171 \text { mulheres } \\
\text { primíparas, } \\
\text { com } 38 \text { a } \\
\begin{array}{ll}\text { semanas } & \text { de } \\
\text { gestação, } & \text { no } \\
\text { Hospital em }\end{array}\end{array}$ & $\begin{array}{l}\text { Estudo } \\
\text { observacional } \\
\text { em que as } \\
\text { participantes } \\
\text { foram divididas } \\
\text { em dois grupos: }\end{array}$ & $\begin{array}{l}\text { A duração do } \\
\text { segundo período } \\
\text { do trabalho de } \\
\text { parto } \\
\text { significativamente } \\
\text { menor no grupo }\end{array}$ \\
\hline
\end{tabular}




\begin{tabular}{|c|c|c|c|c|}
\hline $\begin{array}{l}\text { Preventing } \\
\text { Perineal Trauma } \\
\text { Oglak, S. C., \& } \\
\text { Obut, M. } \\
(2020)\end{array}$ & \begin{tabular}{|l|} 
trabalho de \\
parto na \\
prevenção \\
do trauma \\
perineal
\end{tabular} & $\begin{array}{l}\text { Diyarbakır, } \\
\text { entre janeiro de } \\
2017 \text { e maio de } \\
2019\end{array}$ & $\begin{array}{lr}\text { o grupo } & \text { da } \\
\text { massagem } & \\
\text { perineal e o } & \\
\text { grupo controle. } \\
\text { A massagem } \\
\text { perineal foi } \\
\text { realizada } \\
\text { durante } \\
\text { segundo } \\
\text { período } \\
\text { trabalho do } \\
\text { parto. Após o } \\
\text { parto o períneo } \\
\text { foi examinado }\end{array}$ & $\begin{array}{l}\text { da massagem (36 } \\
\pm 19 \text { minuto) em } \\
\text { comparação com } \\
\text { o grupo controle } \\
(46 \pm 25 \text { minutos, } \\
\mathrm{p}=0,024) \text {. Vinte } \\
\text { cinco mulheres } \\
(28,8 \%) \text { no grupo } \\
\text { da massagem } \\
\text { ficou com o } \\
\text { períneo intacto, } \\
\text { em comparação } \\
\text { com cinco ( } 6,0 \%) \\
\text { no grupo de } \\
\text { controle (p }= \\
0,003) \text {. A taxa de } \\
\text { lacerações } \\
\text { perineais de } \\
\text { primeiro } \\
\text { segundo grau foi } \\
\text { maior no grupo de } \\
\text { massagem } 32,2 \% \\
\text { e } 10,3 \% \text {, } \\
\text { respetivamente, } \\
\text { do que no grupo } \\
\text { controle } 11,9 \% \text { e } \\
6,0 \% \text {, } \\
\text { respetivamente (p } \\
<0,001) \text {. A } \\
\text { incidência de } \\
\text { episiotomia foi } \\
\text { significativamente } \\
\text { menor no grupo } \\
\text { que recebeu } \\
\text { massagem } \\
(28,7 \%) \text { do que no } \\
\text { grupo controle } \\
(76,1 \%, p<0,001)\end{array}$ \\
\hline $\begin{array}{l}\text { 3.Effect } \\
\text { Perineal } \\
\text { Massage on the } \\
\text { Rate } \\
\text { Episiotomy } \\
\text { of } \\
\text { Akhlaghi, F., } \\
\text { Baygi, Z. S., Miri } \\
\text { M., \& Najafi M. } \\
\text { N. } \\
(2019)\end{array}$ & $\begin{array}{l}\text { Investigar o } \\
\text { efeito da } \\
\text { massagem } \\
\text { perineal } \\
\text { durante o } \\
\text { trabalho de } \\
\text { parto sobre } \\
\text { a } \\
\text { necessidade } \\
\text { de } \\
\text { episiotomia }\end{array}$ & $\begin{array}{l}99 \text { parturientes } \\
\text { primíparas } \\
\text { com, entre a } \\
37^{\mathrm{a}} \text { e } 42^{\mathrm{a}} \\
\text { semana de } \\
\text { gestação, no } \\
\text { Razavi } \\
\text { Hospital em } \\
\text { Mashaad, entre } \\
\text { julho e outubro } \\
\text { de } 2018\end{array}$ & 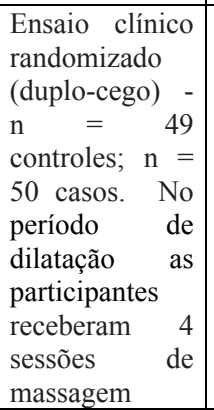 & $\begin{array}{l}\text { A necessidade de } \\
\text { episiotomia foi } \\
\text { significativamente } \\
\text { menor no grupo } \\
\text { em que foi } \\
\text { realizada } \\
\text { massagem } \\
\text { perineal (p }= \\
0,05) \text {. O grau das } \\
\text { lacerações nas } 20 \\
\text { mulheres que não } \\
\text { necessitaram de }\end{array}$ \\
\hline
\end{tabular}




\begin{tabular}{|c|c|c|c|c|}
\hline & & & 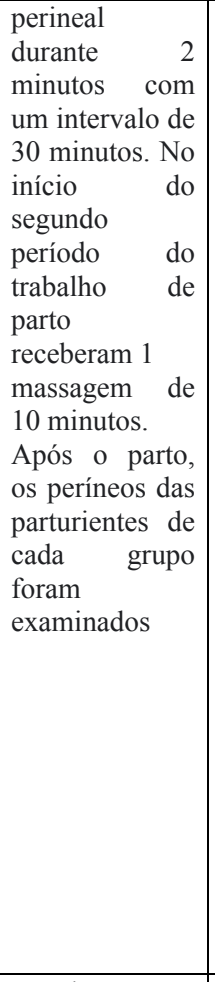 & $\begin{array}{l}\text { episiotomia }(\mathrm{p}= \\
0,5) \text { as que } \\
\text { precisaram ( } \mathrm{n}= \\
79 ; \mathrm{p}=0,1) \text { não } \\
\text { foi significativo, } \\
\text { em ambos os } \\
\text { grupos. No grupo } \\
\text { da massagem as } \\
\text { mulheres que não } \\
\text { necessitaram de } \\
\text { episiotomia (n = } \\
\text { 14) e tiveram } \\
\text { laceração, as de } \\
\text { primeiro grau } \\
\text { foram mais } \\
\text { frequentes do que } \\
\text { as de segundo } \\
\text { grau. A duração } \\
\text { do primeiro e } \\
\text { segundo período } \\
\text { do trabalho de } \\
\text { parto foram } \\
\text { significativamente } \\
\text { menores no grupo } \\
\text { de intervenção em } \\
\text { relação ao grupo } \\
\text { controle (p=0,3; } \\
\text { p=0,002, } \\
\text { respetivamente) }\end{array}$ \\
\hline 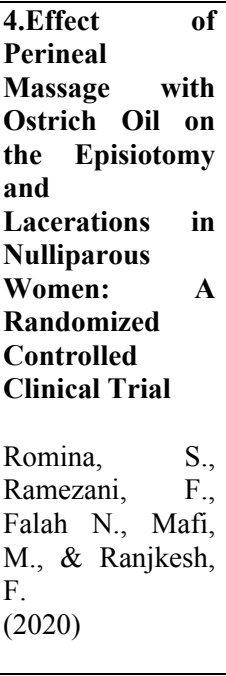 & $\begin{array}{l}\text { Analisar o } \\
\text { efeito da } \\
\text { massagem } \\
\text { perineal } \\
\text { com } \\
\text { óleo de } \\
\text { avestruz na } \\
\text { episiotomia } \\
\text { e } \\
\text { lacerações } \\
\text { em } \\
\text { primíparas }\end{array}$ & $\begin{array}{l}77 \text { mulheres } \\
\text { primíparas, } \\
\text { entre as } 37 \text { e } 42 \\
\text { semanas de } \\
\text { gestação, no } \\
\text { Hospital Razi } \\
\text { em Qazvin, de } \\
\text { maio a } \\
\text { dezembro de } \\
2018\end{array}$ & 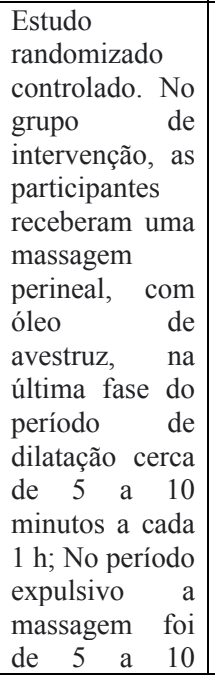 & $\begin{array}{lr}\text { A massagem } \\
\text { perineal com óleo } \\
\text { de avestruz no } \\
\text { grupo } & \text { de } \\
\text { intervenção } \\
\text { diminuiu } \\
\text { significativamente } \\
\text { a taxa de } \\
\text { episiotomia em } \\
\text { comparação com } \\
\text { o controle grupo } \\
\text { (p <0,001). No } \\
\text { entanto, não } \\
\text { houve diferença } \\
\text { estatisticamente } \\
\text { significativa nas } \\
\text { lacerações } \\
\text { perineais entre os } \\
\text { dois grupos. }\end{array}$ \\
\hline
\end{tabular}




\begin{tabular}{|c|c|c|c|c|}
\hline & & & $\begin{array}{l}\text { minutos a cada } \\
30 \text { minutos. } \\
\text { As taxas de } \\
\text { episiotomia e } \\
\text { laceração } \\
\text { perineal foram } \\
\text { comparadas } \\
\text { entre os dois } \\
\text { grupos Os } \\
\text { dados foram } \\
\text { analisados } \\
\text { usando qui- } \\
\text { quadrado, teste } \\
\text { t e Mann- } \\
\text { Whitney } \\
\end{array}$ & \\
\hline 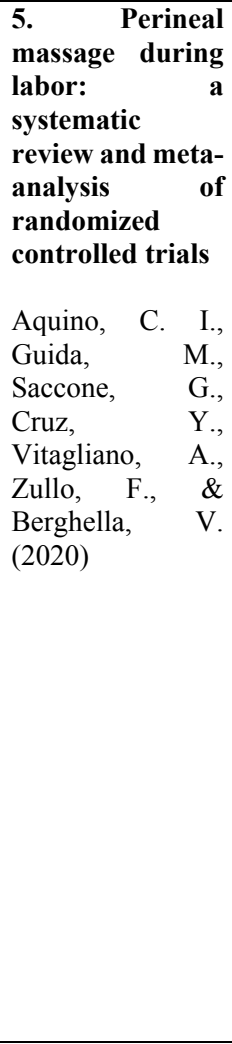 & $\begin{array}{l}\text { Avaliar se a } \\
\text { massagem } \\
\text { perineal } \\
\text { durante o } \\
\text { trabalho de } \\
\text { parto } \\
\text { diminui o } \\
\text { risco de } \\
\text { trauma } \\
\text { perineal }\end{array}$ & \begin{tabular}{|lr} 
Mulheres & \\
primíparas & a \\
partir das & 36 \\
semanas & de \\
gestação & \\
\end{tabular} & 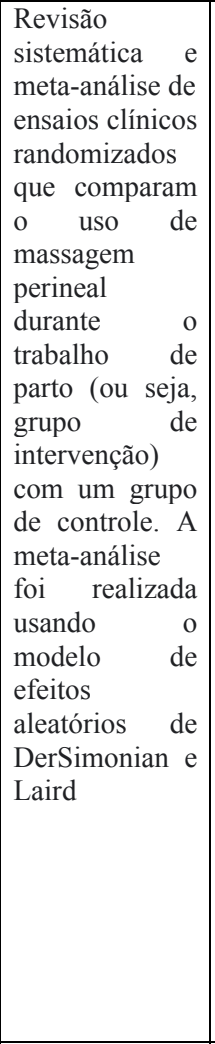 & $\begin{array}{l}\text { Mulheres que } \\
\text { receberam } \\
\text { massagem } \\
\text { perineal tiveram } \\
\text { uma incidência } \\
\text { significativamente } \\
\text { menor de trauma } \\
\text { perineal grave, em } \\
\text { comparação com } \\
\text { aqueles que não } \\
\text { receberam (RR } \\
0,49 \text { IC 95\% } \\
0,25-0,94) \text {. Todos } \\
\text { os resultados } \\
\text { secundários não } \\
\text { foram } \\
\text { significativos, } \\
\text { exceto para a } \\
\text { incidência de } \\
\text { períneo intacto, } \\
\text { que foi } \\
\text { significativamente } \\
\text { maior no grupo de } \\
\text { massagem } \\
\text { perineal (RR } 1,40 \text {, } \\
95 \% \text { 1,01-1,93), } \\
\text { bem como para a } \\
\text { incidência } \\
\text { episiotomia (RR } \\
0,56 \text { IC } 95 \% \\
0,38-0,82 \text { ) }\end{array}$ \\
\hline $\begin{array}{l}\text { 6. Perineal } \\
\text { Massage during } \\
\text { Second Stage of } \\
\text { Labor to the }\end{array}$ & $\begin{array}{l}\text { Determinar } \\
\text { o efeito da } \\
\text { massagem } \\
\text { perineal }\end{array}$ & $\begin{array}{l}\text { 182 primíparas, } \\
\text { no Siloam } \\
\text { Hospital, em } \\
\text { Makassar, } \\
\end{array}$ & $\begin{array}{l}\text { Estudo } \\
\text { controlado não } \\
\text { randomizado. }\end{array}$ & $\begin{array}{l}\text { No grupo da } \\
\text { massagem } \\
\text { perineal, a maioria } \\
\text { das lacerações }\end{array}$ \\
\hline
\end{tabular}




\begin{tabular}{|c|c|c|c|c|}
\hline $\begin{array}{l}\begin{array}{l}\text { Perineal } \\
\text { Laceration } \\
\text { Degree } \\
\text { Primigravida }\end{array} \\
\text { in } \\
\text { Arafah, } \\
\text { Lotisna, D., \&., } \\
\text { Tiro, E. } \\
\text { (2016) }\end{array}$ & $\begin{array}{l}\text { durante o } \\
\text { segundo } \\
\text { período } \\
\text { trabalho de } \\
\text { parto no } \\
\text { grau de } \\
\text { laceração } \\
\text { perineal na } \\
\text { primípara }\end{array}$ & $\begin{array}{l}\text { entre agosto de } \\
2014 \\
\text { fevereiro de } \\
2015\end{array}$ & $\begin{array}{l}182 \text { primíparas } \\
\text { foram divididas } \\
\text { em dois grupos: } \\
103 \\
\text { no grupo da } \\
\text { massagem e } 79 \\
\text { no grupo } \\
\text { controle Os } \\
\text { dados foram } \\
\text { analisados } \\
\text { usando o teste } \\
\text { de qui } \\
\text { quadrado em } \\
\text { SPSS }\end{array}$ & $\begin{array}{l}\text { perineais foram de } \\
\text { primeiro grau } \\
(52,4 \%) \text {, enquanto } \\
\text { que, no grupo de } \\
\text { controle, a } \\
\text { maioria era de } \\
\text { segundo grau } \\
(77,2 \%) \text {. A análise } \\
\text { estatística } \\
\text { mostrou uma } \\
\text { associação } \\
\text { significativa entre } \\
\text { massagem } \\
\text { perineal } \\
\text { diminuição do } \\
\text { grau de laceração } \\
(\mathrm{p}<0,05)\end{array}$ \\
\hline
\end{tabular}

\section{DISCUSSÃO}

Depois de apresentados os resultados da pesquisa, segue-se a confrontaçãode modo a responder à questão de pesquisa e cumprir o respetivo objetivo delineado. Será apresentada em função dos temas emergentes da análise: lacerações, episiotomia, duração do trabalho de parto, e dor.

\section{Lacerações}

Quanto às lacerações perineais segundo o estudo de Arafah, Lotisna, e Tiro (2016) na Indonésia, a percentagem de períneos sem traumatismo foi superior no grupo em que realizaram massagem em relação ao grupo controle. Assim como, no grupo da massagem não ocorreram lacerações de terceiro e quarto grau, enquanto no grupo controle só não ocorreu lacerações de quarto grau. Shahoei, Zaheri, Nasab, e Ranaei (2017), corrobora estes resultados.

Oglak e Obut (2020), no seu estudo verificou, também, a diminuição de lacerações com a realização de massagem perineal, havendo assim um maior número de períneos intactos no grupo de intervenção, em relação ao grupo de controle, sendo que as mulheres que apresentavam trauma perineal, na sua maioria eram lacerações, em que as de primeiro grau cicatrizavam por segunda intenção, sem necessidade de suturar. Neste estudo, em ambos os grupos não ocorreram lacerações de terceiro e quarto grau.

Na revisão com meta análise verificou-se uma menor incidência de lacerações de terceiro e quarto grau nas puérperas que tiveram massagem durante o trabalho de parto. Para além disso, o mesmo autor verificou nos estudos inseridos na revisão que esta relação tem mais impacto em mulheres primíparas em relação às multíparas, uma vez que nas multíparas não houve diferença significativa entre as que tiveram massagem e as do grupo controle (Aquino et al., 2020).

Por último, num estudo realizado em Qazvin, no Irão, por Romina, Ramezani, Falah, Mafi, e Ranjkesh (2020), este analisou o efeito da massagem perineal com óleo de avestruz na episiotomia e lacerações perineais durante a última fase do período de dilatação e o segundo período do trabalho de parto em mulheres primíparas, no entanto, não houve diferenças significativas entre os dois grupos, 0 autor considera que este resultado pode ter sido influenciado pela maneira como foi realizada a massagem. 


\section{EFEITOS DA MASSAGEM PERINEAL DURANTE O TRABALHO DE PARTO}

\section{Episiotomia}

No que toca às episiotomias, sabe-se que, por vezes, ainda continua a ser um procedimento de rotina, mas desnecessário. Sendo assim, alguns estudos encontrados fazem a relação entre a utilização da massagem no períneo e a necessidade de episiotomia. Cinco dos seis estudos analisados referem que a incidência de episiotomia foi, significativamente, menor nos grupos em que se realizou massagem durante 0 trabalho de parto, em relação, aos grupos controle. Nestes estudos a episiotomia quando realizada nunca foi considerada como rotina (Shahoei et al., 2017; Oglak \& Obut, 2020; Aquino et al., 2020; Romina et al, 2020; Akhlaghi, Baygi, Miri, \& Najafi, 2019)

Akhlaghi et al. (2019) considerou ainda que não houve diferenças significativas no grau das lacerações, entre as parturientes em que não foi necessário a episiotomia e as que precisaram. No grupo em que foi realizada massagem perineal, durante o trabalho de parto, as mulheres que não necessitaram de episiotomia e tiveram laceração, as mais frequentes foram de primeiro grau.

No estudo de Romina et al. (2020), já referido, os resultados revelaram que o grupo que recebeu a massagem perineal com óleo de avestruz teve uma diminuição significativa na execução de episiotomia em comparação com 0 grupo de controle.

\section{Duração do trabalho de parto}

Em relação à duração do trabalho de parto, só dois estudos tiveram em consideração este ponto com a realização da massagem perineal. Para Oglak e Obut (2020) a duração do segundo período do parto foi, significativamente, menor no grupo em que foi realizada massagem em comparação com o grupo controle, obtendo uma média de 27 minutos e meio e 35 minutos e meio, respetivamente. Já Akhlaghi et al. (2019) também teve em conta o primeiro período do trabalho de parto, uma vez que a sua intervenção ainda começou nessa fase, obtendo resultados significativos entre 0 grupo controle e 0 grupo da massagem, sendo este último o que obteve menor tempo.

\section{Dor}

Relativamente à dor após o parto, só um estudo evidenciou a mesma no contexto da massagem perineal, em que 0 investigador fez ensinos às mulheres acerca da dor, validando-0s, para posteriormente contactar as mesmas ao terceiro, décimo dia e três meses após o parto. Concluiu, assim, após comparação dos dois grupos que no terceiro dia e três meses após o parto a dor era, significativamente, menor no grupo em que foi realizada massagem perineal. Já ao décimo dia não houve diferenças significativas (Shahoei et al.,2017).

\section{CONCLUSÕES}

A preservação do períneo no parto vaginal é vista cada vez mais como uma preocupação pelo Enfermeiro Especialista em Enfermagem de Saúde Materna e Obstétrica. Mesmo a nível de evidência científica já começam a surgir mais estudos que abordam as estratégias desenvolvidas para prevenir o traumatismo perineal. Relativamente à massagem perineal, no contexto trabalho de parto, verificou-se que efetivamente tem efeitos relacionados com a integridade do períneo, como a diminuição do número de lacerações, sendo as lacerações de terceiro e quarto grau as que menos ocorrem, e a redução no número de episiotomias a ser realizadas, mas também se verificou que há uma redução na duração do trabalho de parto e uma diminuição, substancial, na incidência de dor após o parto.

Ao longo da elaboração desta revisão fui confrontada com algumas limitações inerentes à questão de pesquisa e 0 seu objetivo. Assim sendo, seria importante elaborar mais estudos primários que abordassem a massagem perineal no contexto do trabalho de parto e que tivesse como participantes mulheres multíparas, uma vez que a maioria dos estudos primários existentes aborda a massagem ao períneo só em mulheres primíparas e em contexto pré-natal, assim como seria interessante realizar estudos que envolvessem mulheres que têm prática regular de atividade física. 
Para finalizar, reitera-se a importância de realizar estudos primários acerca da massagem perineal, durante 0 trabalho de parto, mas também em Portugal, por um lado para identificar maternidades que a utilizam e, por outro, verificar os seus efeitos da mesma.

\section{FINANCIAMENTO E AGRADECIMENTOS}

Este trabalho é financiado por Fundos Nacionais através da FCT - Fundação para a Ciência e a Tecnologia, I.P., no âmbito do projeto Ref ${ }^{a}$ UIDB/00742/2020. Agradecemos adicionalmente ao Politécnico de Viseu pelo apoio prestado

\section{REFERENCIAS BIBLIOGRÁFICAS}

Akhlaghi, F., Baygi, Z. S., Miri, M., \& Najafi, M. N. (2019). Effect of Perineal Massage on the Rate of Episiotomy. Journal of Family \& Reproductive Health, 13(3), 160-166

Aquino, C. I., Guida, M., Saccone, G., Cruz, Y., Vitagliano, A., Zullo, F., \& Berghella, V. (2020). Perineal massage during labor: a systematic review and meta-analysis of randomized controlled trials. The journal of maternalfetal \& neonatal medicine: the official journal of the European Association of Perinatal Medicine, the Federation of Asia and Oceania Perinatal Societies, the International Society of Perinatal Obstetricians, 33(6), 1051-1063. https://doi.org/10.1080/14767058.2018.1512574

Arafah, S., Lotisna, D., \& Tiro, E. (2016). Perineal Massage during Second Stage of Labor to the Perineal Laceration Degree in Primigravida. Indonesian Journal of Obstetrics and Gynecology, 218-221. https://doi.org/10.32771/inajog.v4i4.440

Beckmann, M. M., \& Stock, O. M. (2013). Antenatal perineal massage for reducing perineal trauma. The Cochrane database of systematic reviews, (4), CD005123. https://doi.org/10.1002/14651858.CD005123.pub3

Botelho, C. M. (2017). A influência da massagem perineal na incidência do trauma perineal no segundo período de trabalho de parto (Dissertação de mestrado). Obtido de: http://hdl.handle.net/10400.26/18363

Galvão, T. F., Pansani, T. S. A., \& Harrad, D. (2015). Principais itens para relatar Revisões sistemáticas e Metaanálises: A recomendação PRISMA. Epidemiologia e Serviços de Saúde, 24(2), 335342. https://dx.doi.org/10.5123/S1679-49742015000200017

Henriques, A. (2017). Episiotomia e lacerações perineais. In L. Graça (5ª́Ed.), Medicina Materno fetal (pp. 180184). Lisboa: Lidel.

Lowdermilk, D., \& Perry, S. (2006). Enfermagem na Maternidade. Loures: Lusodidacta.Oglak, S., C., \& Obut, M. (2020). Effectiveness of Perineal Massage in the Second Stage of Labor in Preventing Perineal Trauma. Gorm, 26(2), 88-93. https://doi.org/10.21613/GORM.2020.1068

OMS (2018) Intrapartum care for a positive childbirth experience Geneva: World Health Organization. ISBN: 97892-4-155021-5. Acedido em 9789241550215eng.pdf;jsessionid=2CE097C6238C43C557860A1FE42190D1 (who.int)

Romina, S., Ramezani, F., Falah, N., Mafi, M., \& Ranjkesh, F. (2020). Effect of Perineal Massage with Ostrich Oil on the Episiotomy and Lacerations in Nulliparous Women: A Randomized Controlled Clinical Trial. Iranian Journal of Nursing \& Midwifery Research, 25(2), 134-138. https://doi.org/10.4103/ijnmr.IJNMR_76_19

Shahoei, R., Zaheri, F., Nasab, L. H., \& Ranaei, F. (2017). The effect of perineal massage during the second stage of birth on nulliparous women perineal: A randomization clinical trial. Electronic Physician, 9(10), 55885595. https://doi.org/10.19082/5588

Souza, M. T., Silva, M. D., \& Carvalho, R. (2010). Integrative review: what is it? How to do it? Einstein (16794508), 8(1), 102-106. https://doi.org/10.1590/s1679-45082010rw1134

Zukoff, M. K. A., Pereira, A. L. F., Rafael, Ricardo, M. R., \& Penna, L. H. G. (2019). Fatores obstétricos associados à proteção perineal na assistência das enfermeiras obstétricas ao parto normal. Nursing, 22(251), 2856-2861 
